\title{
CHARACTER BUILDING BERBASIS MULTIMEDIA DI PAUD FLAMBOYAN JALAN ATLAS DALAM, KELURAHAN BABAKAN SURABAYA, KECAMATAN KIARACONDONG
}

\author{
Dede Ropik Y \\ ddrofieq@gmail.com \\ Yunia Mulyani \\ yuniams@yahoo.com \\ Sussy Susanti \\ sussy.rebab19@gmail.com
}

\section{SEKOLAH TINGGI ILMU EKONOMI EKUITAS}

\begin{abstract}
ABSTRAK
Pengabdian ini dilaksanakan untuk membantu kesulitan guru dalam membangun karakter khususnya dalam pembinaan akhlak siswa di PAUD Flamboyan, yang berlandaskan keimanan dan ketakwaan. PAUD Flamboyan ini didirikan dengan tujuan untuk meningkatkan ilmu pengetahuan anak yang berlandaskan keimanan bagi anak-anak kurang mampu. Sekolah ini berlokasi di Jl. Atlas Dalam, Kelurahan Babakan Surabaya, Kecamatan Kiaracondong Bandung, murid yang bersekolah di tempat ini sebagian besar orangtuanya bekerja sebagai pedagang kaki lima di sepanjang jalan Kiaracondong. Solusi yang diberikan untuk membantu PAUD tersebut adalah dengan memberikan bantuan peralatan multimedia dan pelatihan penggunaan CD Interaktif pada guru, dari hasil pengabdian ini diharapkan guru dapat menerapkan dalam pelaksanaan pembelajaran di kelas, sehingga siswa dapat mengetahui dan menerapkan hal-hal baik sehingga terbentuk akhlak dan karakter yang baik dalam menjalani kehidupan sehari-hari yang diharapkan dapat melekat hingga dewasa. Setelah pengabdian selesai dilaksanakan dapat disimpulkan bahwa (1) Siswa menjadi aktif dalam menjawab dan mengikuti perintah di layar computer, (2) Siswa termotivasi untuk menghapal doa-doa pendek karena tampilan yang menarik (3) Siswa berani berdiskusi dengan temannya ketika hendak menjawab pertanyaan (4) Siswa berani mencoba menjawab dan tidak takut salah.
\end{abstract}

Kata kunci: Pendidikan karakter, multimedia.

\section{PENDAHULUAN}

Pada usia dini 0-6 tahun, otak berkembang sangat cepat hingga 80 persen. Pada usia tersebut otak menerima dan menyerap berbagai macam informasi, tidak melihat baik dan buruk. Itulah masa-masa yang dimana perkembangan fisik, mental maupun spiritual anak akan mulai terbentuk. Karena itu, banyak yang menyebut masa tersebut sebagai masa-masa emas anak (golden age).

Sebuah penelitian yang dilakukan oleh seorang ahli Perkembangan dan Perilaku Anak dari Amerika bernama Brazelton menyebutkan bahwa pengalaman 
anak pada bulan dan tahun pertama kehidupannya sangat menentukan apakah anak ini akan mampu menghadapi tantangan dalam kehidupannya dan apakah ia akan menunjukkan semangat tinggi untuk belajar dan berhasil dalam pekerjaannya.

Karakter menurut Kamus Besar Indonesia Kontemporer adalah watak, sifat, tabiat. Sedangkan pengertian lain menurut Hornby dan Parnwell, karakter adalah kualitas mental atau moral, nama atau reputasi. Karakter baik dimanifestasikan dalam kebiasaan baik di kehidupan seharihari: pikiran baik, hati baik, dan tingkah laku baik. Berkarakter baik berarti mengetahui yang baik, mencintai kebaikan, dan melakukan yang baik. Pendidikan karakter adalah upaya penanaman nilai-nilai karakter kepada anak didik yang meliputi pengetahuan, kesadaran atau kemauan, dan tindakan untuk melaksanakan nilai-nilai kebaikan dan kebajikan, kepada Tuhan YME, diri sendiri, sesama, lingkungan maupun kebangsaan agar menjadi manusia yang berakhlak.

Meskipun definisi multimedia belum jelas, secara sederhana ia diartikan sebagai lebih dari satu media. Multimedia bisa merupakan kombinasi teks, grafik, animasi, suara dan gambar. Namun pada bagian ini perpaduan dan kominasi dua atau lebih jenis media ditekankan pada kendali computer sebgai penggerak keseluruhan gabungan media ini. Dengan demikian multimedia yang umumnya dikenal dewasa ini adalah berbagai macam kombinasi grafik, teks, suara, video dan animasi. Penggabungan ini merupakan suatu kesatuan yang secara bersama-sama menampikan informasi, pesan atau isi pelajaran

PAUD Flamboyan ini berlokasi di Jalan Atlas Dalam di pinggiran sungai di daerah Kiaracondong yang dikenal dengan daerah yang berpenduduk sangat padat dengan gang-gang yang sangat sempit. https://news.detik.com/berita-jawa-barat/d1242838/permukiman-194-rw-di-bandungkumuh-. Jumlah penduduk Kelurahan
Babakan Surabaya sebanyak 18.483 yang terdiri dari 100 RT dan 14 RW. Profesi orangtua mayoritas pedagang kaki lima. Dalam kesehariannya anak-anak seringkali turut orangtua berjualan disepanjang trotoar. Kebiasaan tinggal dipinggir jalan tersebut menimbulkan dampak yang kurang baik bagi anak-anak tersebut, seperti mjnnnnmisalnya untuk menghabiskan waktu anak-anak terbiasa menonton film yang belum layak bagi usianya dari CD yang dijual orangtuanya, mendengarkan pembicaraan yang belum pantas didengar anak-anak, merokok, dan lain-lain. Berdasarkan permasalahan tersebut maka PAUD ini didirikan oleh ibu Yati dengan tujuan untuk memberikan tempat pada anak untuk bersosialisasi sesuai dengan usianya dan meningkatkan kemampuan pengetahuan anak dengan berlandaskan pada keimanan sedini mungkin. Jumlah siswa PAUD saat ini sebanyak 42 siswa TK dan KB yang ditampung di bangunan sederhana di pinggir sungai.

Selain untuk memperbaiki perilaku dan akhlak pada anak-anak, PAUD ini juga didirikan untuk mempersiapkan anak didiknya memasuki sekolah dasar. Berdasarkan tujuan tersebut maka selain materi pengenalan pendidikan untuk anak usia dini, PAUD juga memberikan pelajaran pengembangan potensi peserta didik untuk menjadi pribadi berperilaku baik yang mencerminkan akhlaqul kharimah anak didiknya. Dalam pemberian materi pengembangan potensi ini guru seringkali mengalami kesulitan menyampaikan materinya, dikarenakan kebiasaan anak usia dini yang konsentrasinya mudah teralihkan sehingga ketika guru mengajar anak-anak mudah merasa bosan dan jenuh.

\section{METODE PELAKSANAAN}

Permasalahan prioritas mitra pengabdian adalah meningkatkan akhlak dan perbaikan karakter siswa melalui pembelajaran yang menarik. Solusi prioritas 
yang diberikan oleh tim pengabdian adalah dengan memberikan $\mathrm{CD}$ interaktif beserta pelatihan penggunaannya. Pelatihan diberikan kepada guru dengan tujuan agar guru dapat menyampaikannya kembali kepada siswa.

Tim pengabdian mempunyai kesepakatan bersama mitra pengabdian, berupa penggunaan $\mathrm{CD}$ interaktif dalam metode pembelajaran sebagai upaya untuk meningkatkan akhlak dan pembentukan karakter siswa.

Prosedur pelaksanaan pengabdian di PAUD Flamboyan adalah sebagai berikut,

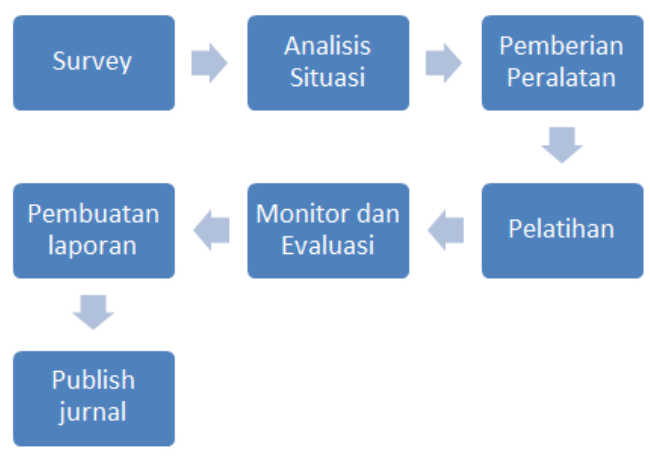

\section{Gambar 1. Prosedur Pengabdian di PAUD Flamboyan}

Prosedur Pengabdian di PAUD Flamboyan diuraikan dalam langkah-langkah kegiatan dibawah ini:

1. Analisis Situasi : Pada tahapan ini tim melakukan upaya untuk memetakan permasalahan utama yang terjadi di tempat pengabdian

2. Berdasarkan hasil analisis situasi ternyata diketahui bahwa permasalahan adalah ketidaksediaan perangkat untuk menunjang pelaksanaan pembelajaran secara multimedia yaitu seperangkat komputer dan LCD Projector.

3. Pelatihan dilakukan sebagai tahapan berikutnya untuk membantu guru dalam menggunakan multimedia sebagai penunjang pendidikan karakter
4. Monitor dan Evaluasi adalah tahapan kegiatan pengawasan untuk mengetahui sejauh mana pemberian alat dan pelatihan dapat memberi manfaat jangka panjang.

5. Pembuatan laporan dilakukan sebagai bukti pelaksanaan pengabdian.

6. Penerbitan ke dalam jurnal pengabdian adalah tahapan akhir yang merupakan tujuan akhir dari pengabdian ini.

7.

\section{HASIL DAN LUARAN}

\subsection{Hasil}

Kegiatan pengabdian kepada masyarakat ini menghasilkan suatu metode penerapan pendidikan karakter di PAUD Flamboyan, yaitu metode pembelajaran berdasarkan multimedia yaitu memanfaatkan program dan perangkat computer sehingga model pembelajarannya lebih interaktif. Metode pembelajaran ini sangat baik diterapkan kepada siswa TK mengingat pada usia tersebut naluri bermainnya masih sangat kuat.

Adapun media untuk melaksanakan pembelajaran interaktif diberikan melalui CD interaktif yang bisa membentuk karakter khususnya karakter Islami yang diperoleh tim pengabdian dan selanjutnya digunakan oleh guru untuk mengajar

\subsection{Luaran}

Luaran yang dicapai dari pengabdian ini adalah pemberian perangkat computer dan CD interaktif kepada PAUD Flamboyan. CD interaktif yang diberikan kepada pihak sekolah seperti 

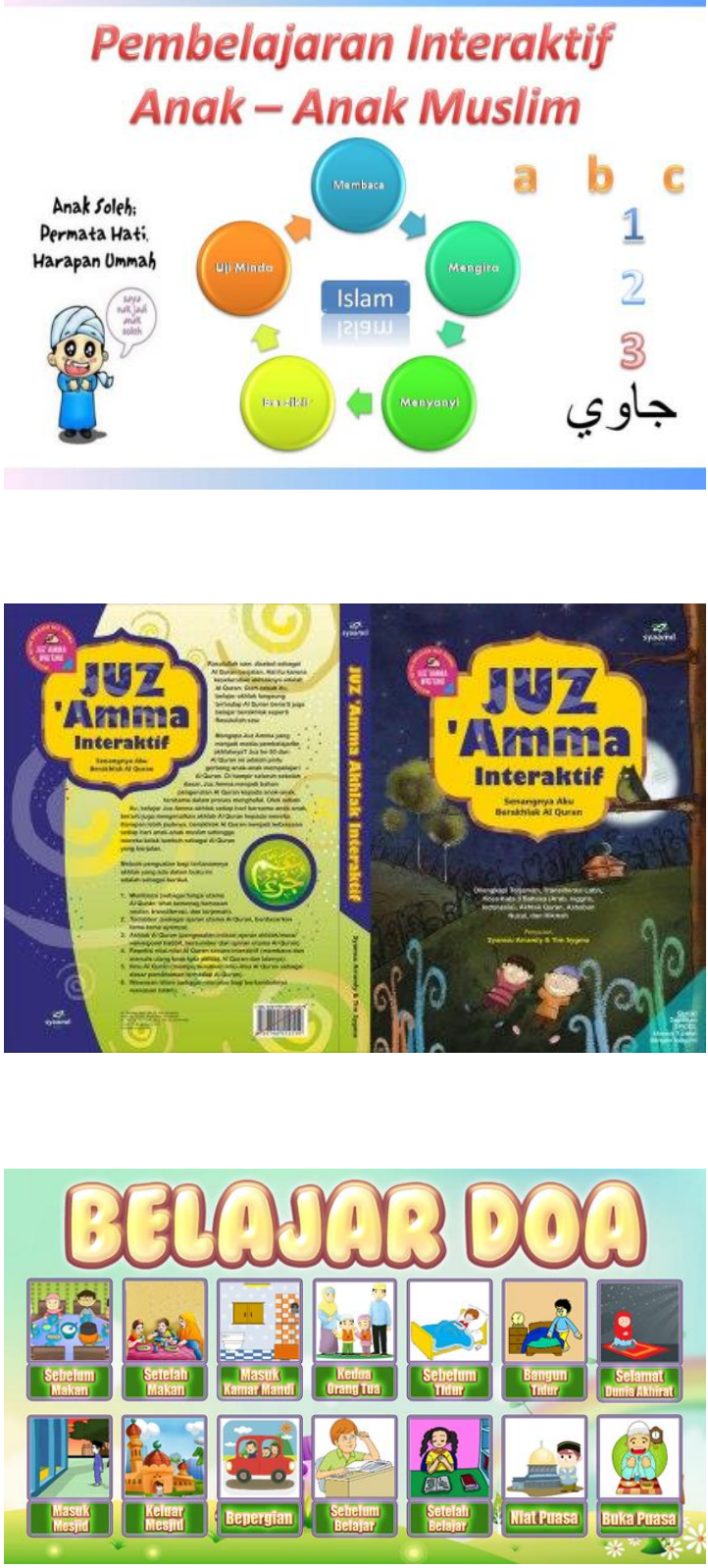

Sedangkan untuk menerapkan pendidikan karakter guru-guru dibekali modul penguatan pendidikan karakter yang dapat di download pada situs ini https://drive.google.com/file/d/0B04ZzQe HOfQxaWhJTzZIRU5IOG8/view

Modul ini terdiri dari 6 modul yaitu:

1. Modul 1 : Kebijaksanaan dan Konsep Dasar PPK

2. Modul 2 : PPK berbasis Kelas
3. Modul 3 : PPK berbasis Budaya Sekolah

4. Modul 4 : PPK berbasis Budaya Masyarakat

5. Modul 5 : Penilaian dan Evaluasi PPK

6. Modul 6 : Desain Rencana Tindak Lanjut

Berikut contoh isi dari modul PPK tersebut

\section{Modul Pelatihan \\ PENGUATAN \\ PENDIDIKAN \\ KARAKTER \\ Bagi Guru}

Modul 1

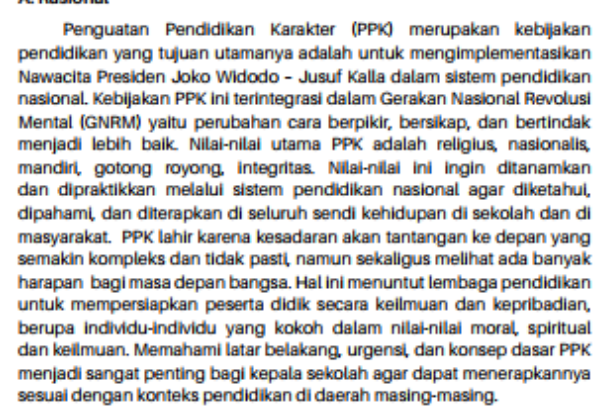

MODUL 1

Kebijakan dan Konsep Dasar PPK

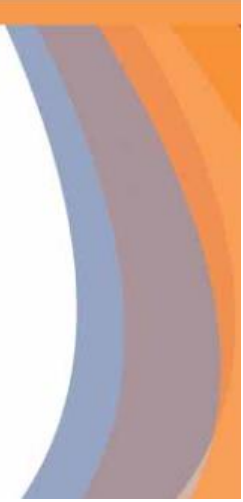


Modul 2

MODUL 2

PPK Berbasis Kelas
Modul 5

MODUL 5

Penilaian dan Evaluasi PPK

Modul 3

Modul 6

MODUL 3

PPK Berbasis Budaya Sekolah

\begin{abstract}
A. Rasional
Penguatan Pendidilkan Karakter (PPW) berbasis budaya sekolah memotret berbagai macam bentuk pembiasaan, model tata kelola yang mendukung PPK Proses penbudayaan menjadil sangat penting dalam penguatan pendidikan karakter karena dapat memberikan atau membangun nillai-nilai luhur kepada generasi muda. Budaya sekolah yang baik diharapkan dapat mengubah perilaku peserta didilik menjact lebih balik. PPK berbasis budaya sekolah mengembangkan berbage macam corak relasi kegiatan dan interaksi antar individu dil lingkungan sekolah yang mengatasi sekat-sekat kelas yang membentuk ekosistem

Membangun budaya sekolah yang baik dapat dillakukan melalui kegiatan-keglatan di sekolah Contoh kegiatan yang dapat dikembangkan dalam membangun budaya sekolah adalah 1) pembiasaan dalan kegiatan inerasi, 2/ keglatanekstrakunkuler, yang mengintegrasikan nilaknillai utama PPK dan 3) menetapkan dan mengevaluasi tata tertib atau iklim akademik yang kompetitif dan kolaboratif, yang diperlukan sekola dalam menetapkan atau memperkuat branding sekolah.
\end{abstract}

\section{Modul 4}

MODUL 4

PPK Berbasis Masyarakat

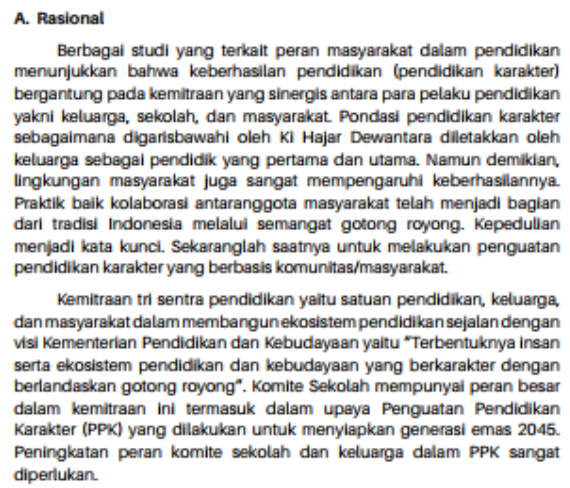

Berbagai studl yang terkait peran masyarakat dalam pendidikan menunjukkan bahwa keberhasilan pendidikan (pendidikan karakter) bergantung pada kemitraan yang sinergis antara para pelaku pendidikan yakni keluarga, sekolah, dan masyarakat. Pondasi pendidikan karakter sebagaimana digansbawanh oleh $\mathrm{il} \mathrm{Hajar} \mathrm{Dewantara} \mathrm{diletakkan} \mathrm{oleh}$ keluarga sebagal pendidik yang pertama dan utama. Namun demikian, Praklik belk kolabos

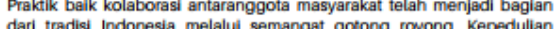
dan ind kepedulan menjadi kata kand, sekaranglahn saatnya untuk melakukan penguatan Kemitraan tri sentra pendidikan yaitu satuan pendidikan, keluarga, dan masyarakat dalammembangunekosistem pendidikan sejalan dengan visi Kemententan Pendidikan dan Kebudayaan yaitu "Terbentuknya insan serta ekosistem pendidikan dan kebudayaan yang berkarakter dengan

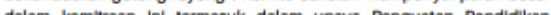
Karakter (PPS) yang dilakukan untuk mpya Penguatan Pendidikan Peningkatan peran komite sekolah den keluerge delam PPK sangen diperlukan.

\begin{abstract}
Rasiona
Gerakan Penguatan Pendidikan Karakter (PPK) yang sudah didesain oleh sekolah/ satuan pendidikan perlu dievaluasi untuk menilai apakah gerakan PPK menerapkan seluruh prinsip penguatan PPK sehingga tujuan pendidikan karakter itu tercapai. Evaluasi dan penilaian PPK dilakukan terhadap desan awal progran (asesmen awall, implementast, dan desain prog pela implement desain program, implementasi, dan evaluasi implementasi dipergunakan

Evaluasi dan penilaian program PPK ini tidak dilakukan untukmenilai dan mengevaluasi individu per individu, melainkan untuk mengukur dampak program PPK. Hasilnya diharapkan dapat menjawab pertanyaan apakah yang dillakukan sekolah sudah memenuhi harapan seperti yan ditetapkan dalam prinsip-prinsip pengembangan PPK? Penilaian peserta didlik secara individual dilaksanakan sesuai dengan kebiljakan penilaian dalam Kurikulum 2013 yang berlaku.
\end{abstract}

\section{MODUL 6 \\ Desain Rencana Tindak Lanjut}

\section{KESIMPULAN}

Membentuk karakter dengan menggunakan model pembelajaran interaktif ini dapat memberikan kesimpulan yaitu :

1. Metode interaktif yang
menggunakan Game edukasi ini
merupakan sebuah game yang di
samping bermain juga dapat
digunakan untuk belajar anak


sehingga anak lebih cepat untuk menangkap materi pembelajaran.

2. Aplikasi Media Pembelajaran ini menggunakan musik, gambar dan animasi sehingga lebih menarik anak untuk belajar.

Hasil yang nyata terlihat setelah

pembelajaran interaktif diberikan yaitu,

1. Siswa menjadi aktif dalam menjawab dan mengikuti perintah di layar computer

2. Siswa termotivasi untuk menghapal doa-doa pendek karena tampilan yang menarik

3. Siswa berani berdiskusi dengan temannya ketika hendak menjawab pertanyaan

4. Siswa berani mencoba menjawab dan tidak takut salah

\section{DAFTAR PUSTAKA}

Arsyad, Azhar (2002). Media Pembelajaran.

Jakarta : PT Raja Grafindo Persada

Baba. (2003). Animasi Kartun dengan Flash

Mx. Jakarta : PT Elek Media

Komputindo

DePorter, Bobbi \& Reardon, Mark. (2013).

"Coordinating positive school culture.

Threes steps to ballance vision and practice". Dalam Principal,

November/December, hlm. 8-11.

http://sdnbanaran1.blogspot.co.id/2017/04/ modul-penguatan-pendidikan-karakter.html

https://drive.google.com/file/d/0B04ZzQe HOfQxaWhJTzZIRU5IOG8/view 